\title{
CARACTERÍSTICAS DEMOGRÁFICAS E A VOLUNTARIEDADE DA MIGRAÇÃO
}

\author{
Marden Barbosa de Campos ${ }^{1}$
}

"A disciplina procede em primeiro lugar à distribuição dos indivíduos no espaço" (Foucault, 2008).

\begin{abstract}
Embora os deslocamentos populacionais sejam normalmente divididos entre movimentos forçados ou voluntários, a maior parte das migrações dificilmente irá enquadrar-se em um desses tipos extremos. O objetivo deste artigo é discutir, conceitualmente, como a idade e o sexo atuam sobre o comportamento migratório, configurando tipos específicos de migrantes cujos deslocamentos possuem diferentes "graus" de voluntariedade. Dar-se-á destaque às relações de poder envolvidas no processo de tomada de decisão para a migração, que fazem com que as migrações de muitos indivíduos sejam um fenômeno involuntário, na medida em que estes não participam ou não tem seus interesses levados em conta durante o processo. $\mathrm{O}$ artigo destaca a importância de considerarmos que a maior parte dos indivíduos não migra só ou não tem a migração como um projeto exclusivamente pessoal e que, mesmo aqueles que migram de maneira forçada, muitas vezes provocam a migração de outros cujo estímulo migratório é determinado por relações de dependência, suporte ou afeto. Destaca a importância de estarmos atentos para as mudanças nas formas de organização social que interferem nesse processo, assim como em suas implicações para a configuração do significado atual da mobilidade espacial da população.
\end{abstract}

Palavras chave: migração forçada, seletividade, relações de poder.

\section{Introdução}

Qualquer deslocamento espacial pode ser considerado, pelo menos teoricamente, como sendo totalmente voluntário ou completamente forçado. $\mathrm{Na}$ prática, contudo, dificilmente um tipo de migração irá enquadrar-se em um desses

\footnotetext{
1 Instituto Brasileiro de Geografia e Estatística. Rio de Janeiro, RJ, Brasil.
} 
tipos extremos. Apenas em termos imaginários podemos considerar a migração como um ato completamente autônomo e voluntário. Por outro lado, dificilmente o indivíduo não possui nenhuma capacidade de escolha frente à necessidade de migrar, mesmo quando a força que o impele a esse ato é extremamente grande.

Entre os diferentes aspectos que influenciam a propensão para migrar e que contribuem para a onipresença de uma "seletividade" da migração, destacam-se a idade e o sexo. Estas características, interagindo com contexto em que os indivíduos vivem, determinam quais indivíduos em uma população irão tornar-se ou não migrantes. Além disso, a seletividade da migração promove uma diferenciação dos migrantes entre aqueles que realizaram atos tipicamente voluntários ou que se submeteram a deslocamentos com um alto grau de "força externa" ao indivíduo.

O objetivo deste artigo é discutir, conceitualmente, como a idade e o sexo atuam sobre o comportamento migratório, configurando tipos específicos de migrantes cujos deslocamentos podem ser considerados como forçados ou como voluntários. Desse modo, busca-se destacar a contribuição da análise demográfica para a discussão teórica da noção de migração forçada. Dar-se-á destaque às relações de poder e sua ligação com ações que levam ou inibem a decisão migratória, com ênfase no âmbito familiar. Esse argumento está baseado na ideia de que, durante o processo de tomada de decisão para a migração, características individuais determinam posições diferenciadas para os membros da família.

Grande parte do debate sobre migrações forçadas concentra-se nos deslocamentos cujo componente involuntário é extremamente elevado, dadas as implicações jurídicas, humanitárias e diplomáticas que envolvem as chamadas "migrações forçadas" e a questão dos refugiados. Isso por vezes leva à ilusão de que os demais tipos de migração que não envolvem um caráter de agressividade ou violência explícita são deslocamentos movidos por uma vontade individual e soberana, pacíficos e, em última instância, não conflituosos. Contudo, conforme discute-se neste trabalho, as relações de poder envolvidas no processo de tomada de decisão para a migração fazem com que as migrações de muitos indivíduos sejam um fenômeno involuntário, na medida em que não participam ou não têm seus interesses levados em conta durante o processo de tomada de decisão.

O artigo inicia com uma breve discussão dos aspectos teóricos desenvolvidos para explicar a ocorrência de migrações "voluntárias", mostrando a importância da análise das relações de poder para melhor entendimento desses deslocamentos. Em seguida, discute os ganhos que podem ser obtidos nos estudos migratórios com a incorporação das relações familiares nas análises de migração. Parte então para uma apresentação do papel da seletividade da migração ao sexo e à idade, mostrando sua influência no poder de decisão do migrante. 


\section{O debate em torno das motivações para a migração}

Migrar sempre foi uma das estratégias de sobrevivência mais importantes para a humanidade, frente a eventos de causa natural, humana e na busca de suprir necessidades que não podem ser atendidas nos locais habitados. Kingsley Davis, ao desenvolver a Teoria das Respostas Multifásicas, em 1963, incluiu a migração em tempos modernos como uma das reações dos indivíduos - ao lado do adiamento do casamento, do celibato, do aborto e da contracepção - aos estímulos sociais e econômicos surgidos durante a modernização ${ }^{2}$. Contudo, a definição das causas precisas para a ocorrência da migração nunca foi consenso entre os estudiosos do tema.

As teorias sobre migração são marcadas por uma grande fragmentação teórica e forte compartimentalização das análises. Desse modo, existem tipologias que diferenciam os migrantes de acordo com a permanência, a distância, a natureza das fronteiras cruzadas e as características dos migrantes. Além disso, uma das mais marcantes diferenciações entre os tipos de migração é a que separa os deslocamentos entre forçados e voluntários.

Em termos conceituais, podemos imaginar um continuum contendo, em seus pontos extremos, de um lado migrações completamente forçadas e de outro migrações totalmente voluntárias, conforme apresentado na Figura 1. Os pontos intermediários desse continuum conteriam os movimentos com diferentes "graus de voluntariedade", que aproximamos migrantes de um ou outro extremo.

FIGURA 1 - Continuum da motivação para a migração

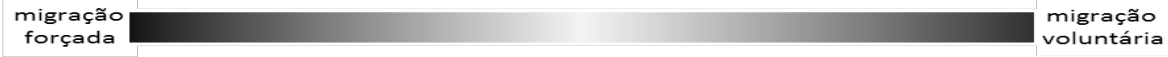

Fonte: adaptado de Hugo, 1996

É fácil imaginar, pelo menos teoricamente, deslocamentos que se localizariam nas duas extremidades do continuum. Entretanto, raramente um movimento migratório pode ser considerado como totalmente voluntário ou completamente forçado. Algumas migrações aproximar-se-iam do extremo das migrações voluntárias (lado esquerdo da FIGURA 1), em que a vontade e o desejo individual predominam como motores do deslocamento. Outras estariam mais próximas do extremo forçado (lado direito), em que forças externas aos indivíduos seriam os principais determinantes de suas migrações. Nesse sentido, um deslocamento só pode ser considerado, em termos estritos, como sendo involuntário se a pessoa for fisicamente transportada de um lugar para outro e não tiver oportunidade de escapar. Teoricamente, mesmo movimentos sob ameaça direta à vida contêm algum elemento de voluntariedade, na medida que há opção de esconder-se, permanecer no local e buscar formas para

2 DAVIS, Kingslay. The theory of change and response in modern demographic history. 
evitar perseguição ${ }^{3}$. Além disso acrescentaríamos que, em casos extremos, o indivíduo pode preferir não migrar e morrer, como acontece, por exemplo, em áreas contaminadas por acidentes nucleares ${ }^{4}$. Nesse sentido, conforme destaca Petersen $^{5}$, mesmo que os fatores de expulsão exerçam forte influência sobre a decisão de migrar, o migrante normalmente ainda mantém algum poder de ficar. Por outro lado, grande parte das migrações que convencionalmente são vistas como deslocamentos voluntários ocorrem em situações em que, de fato, os migrantes possuem pouca ou nenhuma escolha ${ }^{6}$. Nesse sentido, a atribuição de uma objetividade racional à migração, baseada numa análise de custo-benefício seria apenas aparente, dado que a escolha realizada pelo migrante seria sua única alternativa de "sobrevivência".

A partir dessa discussão percebe-se que o ponto central da distinção entre movimentos forçados ou voluntários surge da concorrência entre forças "externas" ou "internas" ao migrante. Mas determinar se o estímulo para a migração parte ou não do indivíduo, assim como a carga de racionalidade supostamente envolvida em qualquer decisão de migrar é uma tarefas extremamente difícil. Essa determinação parte, inicialmente, da escolha da unidade privilegiada de análise da migração, dando ênfase no indivíduo ou no grupo social em que ele vive.

A dificuldade em atribuir uma unidade de análise ou nível da escala que seja adequado para o estudo do processo de decisão não é um problema exclusivo das análises de migração, inserindo-se no antigo debate que ocorre nas ciências sociais sobre qual seria o locus privilegiado da ação social: ação individual (agência) ou estrutura social. Segundo Alexander ${ }^{7}$ na sociologia do pós-guerra houve uma divisão entre escolas radicais de microteorização, que destacavam a centralidade da negociação individual e o caráter contingente da ordem social e, por outro lado, escolas de macroteorização, que enfatizavam o papel de estruturas coercitivas na determinação do comportamento individual e coletivo.

Nas análises da migração, esse tipo de conflito surge, por exemplo, quando nos debruçamos sobre uma das principais correntes teóricas desenvolvida para explicar as migrações: a escola microeconômica. Essa abordagem perdurou por décadas e ainda persiste como um poderoso arcabouço explicativo da migração. Segundo ela, a migração é vista como um processo de escolha racional e investimento pessoal. Os indivíduos migram com base na avaliação de custo-benefício e a migração ocorre quando seu resultado líquido, em termos de utilidade, é positivo ${ }^{8}$. Adotando essa perspectiva, os indivíduos são vistos

\footnotetext{
3 HUGO, Graeme. Environmental concerns and international migration.

4 VIINAMÄKI, Heimo et alii. The Chernobyl accident and mental wellbeing - a population study.

PETERSEN, William. A General Typology of Migration.

6 HUGO, op. cit.

ALEXANDER, Jeffrey. Novo movimento teórico.

8 SJAASTAD, Larry. Os custos e os retornos da migração; BORJAS, George. Labor Economics.
} 
como agentes maximizadores que operam sobre completa racionalidade. Nesse sentido, a migração em busca de trabalho ou de melhores salários seria vista como um deslocamento "totalmente voluntário".

Entretanto, em anos recentes, a racionalidade dos agentes econômicos tem sofrido duras críticas de linhas de pensamento como a economia comportamental, que une aspectos da teoria econômica com descobertas da psicologia e ciência cognitiva. A entrega do Prêmio Nobel de Economia de 2002 a um psicólogo comportamental, Daniel Kahneman, com uma vasta obra dedicada a mostrar a ilusão da noção de completa racionalidade no processo decisório, ilustra o reconhecimento, por parte dos economistas, da limitação da racionalidade individual no processo de tomada de decisão. Segundo Thaler e Mullainathan ${ }^{9}$, é normal que as pessoas adotem regras gerais de comportamento sem nenhuma reflexão, como uma forma de economizar "esforço cognitivo". Os indivíduos agem sobre forte influência de aspectos inconscientes e, mesmo sob tentativa de raciocínio, estão submetidos a vieses comportamentais que os mantém longe da suposta "racionalidade completa"10.

As abordagens que enfatizam a centralidade dos processos macrossociais extraem completamente da agência individual o poder da decisão de migrar e, com isso, reduzem a possibilidade de que um deslocamento seja considerado como "completamente" voluntário.

Com base em uma perspectiva oposta, concentrando-se no processo de estabelecimento das relações capitalistas de produção e consequente expropriação dos meios de produção individuais, podemos enxergar a alienação ou a proletarização da força de trabalho e a imposição do trabalho assalariado como principal forma de sobrevivência e reprodução social. Desta forma, seguir a dinâmica do mercado de trabalho tornou-se uma atitude "normal" e, desse modo, migrar em busca de emprego ou de melhores salários passa a ser considerado com um processo "voluntário" de deslocamento espacial.

Contudo, caso façamos uma crítica deste sistema, então não veremos nenhuma "normalidade" nas migrações em busca de trabalho, mas enxergaremos, ainda que subliminarmente, deslocamentos "forçados" em busca de sobrevivência, em um sistema que beneficia os detentores dos fatores de produção e dos recursos financeiros. Esse seria o mote das abordagens históricoestruturalistas, corrente teórica importante para os estudos de migração, que em lugar de decisões racionais e de estratégias de comportamento individual, qualifica as migrações como sendo condicionadas por processos socioeconômicos que refletem a dinâmica estrutural e espacial dos determinantes (macro) sociais ${ }^{11}$.

9 THALER, Richard H., MULLAINATHAN, Sendhil. How behavioral economics differs from traditional economics.

${ }^{10}$ KAHNEMAN, Daniel. Rápido e devagar: duas formas de pensar.

11 GAUDEMAR, Jean-Paul. Mobilidade do trabalho e acumulação do capital. 
Ao contrário da liberdade de movimento (individualismo), os atores estão sujeitos às pressões do sistema social ${ }^{12}$. Paul Singer, autor de destaque nessa corrente teórica, trata as migrações como um processo social em que a unidade atuante não é o indivíduo, mas o grupo em que este se insere ${ }^{13}$.

Conforme salientado, não nos interessa discutir hipóteses extremas sobre a mobilidade espacial nem defender uma determinada perspectiva (macro ou micro) para explicar a ocorrência e a voluntariedade da migração. Seguindo a tendência recente de não defender a predominância de uma única escala de análise do comportamento social, mas sim articular perspectivas conflitantes, pretendemos criar um diálogo entre agência e estrutura e, consequentemente, localizar as migrações entre deslocamentos que não podem ser completamente voluntários e nem forçados.

A articulação entre diferentes níveis de análise sofre influência de ideias como as contidas na Teoria da Estruturação, desenvolvida por Anthony Giddens, que destaca a condição reflexiva dos agentes frente às mudanças na estrutura da sociedade. SegundoGiddens ${ }^{14}$, as estruturas, entendidas como instituições normativas da sociedade, surgem como resultado das práticas e ações diárias dos indivíduos, sejam elas intencionais ou não. Subsequentemente, a estrutura molda (permitindo ou constrangendo) as ações das pessoas, fornecendo uma gama de possibilidades de ação. Enquanto algumas ações individuais rotineiras reproduzem as estruturas, outras ações possuem autonomia e reflexividade, modificando o comportamento individual e fornecendo as bases para a criação de novas estruturas. Esta perpétua recriação da estrutura através da ação individual (agency) seria a representação da natureza "reflexiva" da vida social ${ }^{15}$. Desse modo, passa-se a enxergar a ligação entre o homem e o mundo de forma dialética, em que o produtor e seu produto atuam reciprocamente um sobre o outro ${ }^{16}$. Esse tipo de raciocínio favoreceu, em anos recentes, o surgimento de perspectivas que destacam a escalas médias ou intermediárias (nível meso) nas análises de migração, que articulam aspectos macro e microestruturais ${ }^{17}$. É o caso, por exemplo, das análises de migração que deslocam a unidade de análise do indivíduo para a família. Esse tem sido, segundo De Hass ${ }^{18}$, um dos grandes avanços teóricos dos estudos da migração.

Interessa-nos, nesse sentido, compreender o jogo de forças que opera entre os indivíduos, famílias e sociedade e que acarreta em migração. Para

12 REZENDE, Dimitri Fazito. Reflexões sobre os sistemas de migração internacional: proposta para uma análise estrutural dos mecanismos intermediários.

${ }^{13}$ SINGER, Paul. Migrações internas: considerações teóricas sobre o seu estudo.

${ }^{14}$ GIDDENS, Anthony. The Constitution of Society: outline of the theory of structuration.

15 TURNER, Jonathan. The theory of structuration.

${ }^{16}$ BERGER, Peter, LUCKMANN, Thomas. A Construção Social da Realidade: tratado de sociologia do conhecimento.

17 FAIST, Thomas. The Crucial Meso Level.

${ }^{18}$ DE HAAS, Hein. Migration and development: a theoretical perspective. 
isso, as relações de poder que operam entre estes níveis são fundamentais para compreender o processo de tomada de decisão da migração e a atribuição de voluntariedade ou não ao ato migratório.

Alguns aspectos do conceito de poder apresentado por Michel Foucault servem-nos para a presente análise, dado que ultrapassam as relações extremas, de coerção e violência, dirigindo-se para as "engrenagens" das relações de poder que operam em microescalas, influenciando comportamentos e ações individuais. Foucault, ao invés de tratar do poder na esfera do Direito ou como algo que tem origem fixa no Estado, destaca a importância de captar o poder em suas "extremidades e ramificações", onde ele é "capilar"19. Nesse sentido, busca-se conhecer a mecânica das relações de poder que configuram as ações que induzem outras ações e que atravessam todo o corpo social. A sutileza com que Foucault aborda o poder é-nos extremamente útil, quando queremos analisar as capacidades e possibilidades de cada indivíduo decidir sobre o ato de migrar, com foco em suas relações com outros indivíduos com quem convivem proximamente, como os familiares. Segundo o autor, as relações de poder atuam "entre cada ponto do corpo social, entre homem e mulher, entre membros de uma família". Não se quer dizer aqui, é preciso esclarecer, que o poder tem origem na família e recai sobre o indivíduo, mas sim que ele "atravessa" as relações familiares, configurando-as e influenciando o comportamento individual. Desse modo, mais do que uma instância negativa, que tem por função reprimir, esse poder é exercido apenas sobre sujeitos livres e apenas quando estão livres ${ }^{20}$. O que faz com que o poder se mantenha e que seja aceito é simplesmente que ele não pesa só como uma força que diz não mas, de fato, que permeia, produz coisas, induz ao prazer e forma saber. Ele atua sob a condição de liberdade de quem sofre a influência, e por isso, pressupõe a capacidade de reação. Vê-se que o conceito do autor tira muito da carga de negatividade que a palavra poder costuma empregar, embora no conjunto de sua obra, também enfatize as formas de dominação em que a sociedade capitalista se submete. Contudo, o que interessa para a presente análise é a capacidade de perceber os diferenciais de poder presentes nas relações familiares que, em grande parte, não são completamente negativos para os envolvidos nos processos de decisão, mesmo que estes possuam pouca ou nenhuma capacidade de reagir. Conforme será destacado mais adiante, o fato de uma criança não decidir sobre sua migração e migrar acompanhando a família não significa que haja um problema e uma forma de violência contra a criança. Significa apenas que a migração da criança não é um ato voluntário embora, ainda assim, seja benéfico para ela.

Interessa-nos destacar como as características demográficas dos indivíduos afetam o processo de tomada de decisão sobre a migração, ao contribuírem

${ }^{19}$ FOUCAULT, Michel. Microfísica do poder.

${ }^{20}$ FOUCAULT, Michel. O sujeito e o poder. 
para a atribuição de determinadas posições dentro da família. Isso nos levaria a repensar os conceitos de migração voluntária e migração forçada, não só no sentido de redefini-los, mas também de desassociá-los de sua carga valorativa, que normalmente equipara esses dois tipos ideais de migração com as noções de migrações "boas" ou "más".

A próxima seção apresenta as formas como a migração é afetada pelas relações familiares e pelo sexo e idade dos migrantes, buscando destacar como as características demográficas afetam as relações de poder que interferem no comportamento migratório.

\section{Famílias e migração}

As famílias são um dos principias "arranjos" que os seres humanos adotam para prover suporte, assistência e companhia aos indivíduos. Os laços familiares, baseados em relações de consanguinidade ou "parentesco" (casamento, mesma criação, adoção) talvez sejam uma das estratégias de sobrevivência de maior sucesso na história da humanidade. Estabelece-se, desse modo, uma espécie de "pacto intergeracional", no sentido proposto por Caldwell ${ }^{21}$. Nas famílias, criam-se pactos entre indivíduos com diferentes "capacidades" como, por exemplo, entre indivíduos de idades diferentes. Trata-se de um tipo de instituição que viabiliza uma série de trocas envolvendo custos, benefícios, altruísmo, cooperação, conflito e externalidades, entre outros aspectos. Além disso, as famílias servem de instância primária de socialização do indivíduo, dotando-o dos atributos necessários para a vida comunitária. Ao mesmo tempo, o sistema familiar cobra do indivíduo atitudes que o façam cooperar, tanto em termos de tornar-se um provedor de serviços e recursos para os outros como, quando no papel de receptor de auxílio, se submete a uma condição de dependência. Assim, estabelecem-se papeis e posições específicas, condicionando os atos de barganha e negociação para tomada de decisão. Nesse processo, há uma divisão de poderes que afeta consideravelmente os resultados das decisões. Foge aos propósitos deste trabalho discutir as relações familiares em profundidade. Contudo, é importante destacar que questões familiares como tomada de decisão sob conflito ou cooperação e alocação intra domiciliar dos recursos são temáticas relevantes para o estudo da migração.

Uma das principais características das famílias que tem forte influência sobre o comportamento migratório baseia-se nos laços estabelecidos entre seus membros. Esses laços pessoais são extremamente fortes entre familiares e, por isso, possuem um papel central na formação de redes sociais. Segundo Granovetter ${ }^{22}$, a força de um laço é definida pela combinação de quantidade de tempo, intensidade emocional, intimidade, confiança e reciprocidade da relação interpessoal. Fica claro, nesse sentido, a importância dos laços familiares e a coesão das redes sociais

\footnotetext{
${ }^{21}$ CALDWELL, John. Towards a restatement of demographic theory.

${ }^{22}$ GRANOVETTER, Mark. The Strength of Weak Ties.
} 
por eles conformadas. No caso das migrações, as redes sociais são definidas como os conjuntos de laços interpessoais que ligam potenciais migrantes com migrantes de fato e com não-migrantes, nas áreas de origem e destino das migrações, via relações de parentesco, amizade e naturalidade ${ }^{23}$. Os contatos dos migrantes desempenham um papel fundamental na propensão migratória, por proverem informações que reduzem o risco da migração, eliminam custos e diminuem as incertezas dos deslocamentos. Nesse sentido, são uma espécie de capital "intangível" (capital social) que os migrantes possuem²4.

Outro ponto importante na relação entre família e migração é que, grande parte das vezes, os membros do domicílio são levados ou inibidos a migrar devido à migração de outro morador. Mincer ${ }^{25}$, em trabalho sobre migração familiar, classifica os indivíduos como tied movers ou tied stayers. Um tied mover seria o indivíduo que individualmente não migraria, mas devido o ganho associado com a mobilidade do outro familiar mais do que compensa os custos de sua mobilidade, sendo assim "levado" a migrar. Já um tied stayer é o indivíduo que individualmente teria motivos para migrar, mas não migra dado que os ganhos com a migração não compensam os custos atribuídos a outros membros da família. Em suma, os custos e benefícios individuais da migração são distribuídos entre os membros da família e a migração só ocorrerá quando o ganho agregado da família for maximizado.

Assim, ao colocar o comportamento do indivíduo em um contexto social mais amplo e considerar não o indivíduo, mas a família como a mais apropriada unidade de tomada de decisão, ganha-se na compreensão do processo de tomada de decisão da migração.

Em termos de teorias de migração, segundo De Haas² ${ }^{26}$, essa foi uma inovação crucial que ocorreu recentemente no campo da migração. É o caso de perspectivas como a Nova Economia da Migração do Trabalho, em que a mobilidade é vista, explicitamente, como uma das estratégias de caráter familiar ${ }^{27}$. Por essa abordagem, alguns dos membros da família migram para trabalhar em setores econômicos onde os rendimentos são negativamente correlacionados com a região em que a família vive, em uma estratégia familiar de proteção ao risco $^{28}$.

Interessa-nos destacar que a migração familiar e os processos de tomada de decisão nem sempre ocorrem com equivalência. São processos de barganha que explicitam uma diferença nas relações de poder. Desse modo, alguns autores

\footnotetext{
${ }^{23}$ LITWIN, Howard. The Social Network of Elderly Immigrants: an analytic typology; MASSEY, Douglas. Social structure, household strategies and the cumulative causation of migration.

${ }^{24}$ TAYLOR, J. Edward. Differential migration, networks, information and risks.

${ }_{25}$ MINCER, Jacob. Family Migration Decisions.

${ }^{26}$ DE HAAS, op. cit.

27 STARK, Oded, BLOOM, David. The new economics of labor migration; STARK, Oded, TAYLOR, J. Edward. Migration incentives, migration types: the role of relative deprivation.

${ }^{28}$ STARK, BLOOM, op. cit.
} 
fazem críticas severas às teorias de migração familiar, principalmente no ponto em que sugerem que existe uma "cooperação" entre os membros da família. Segundo Lawson ${ }^{29}$, por exemplo, existe uma forte conotação de gênero na seleção dos migrantes e, ao invés de cooperação, o que impera no nível intradomiciliar são relações baseadas em poder de barganha, onde geralmente a mulher sai em desvantagem. Do mesmo modo, indivíduos de diferentes idades participam de forma desequilibrada nos processos de tomada de decisão.

Nas próximas seções, trataremos desses aspectos com maiores detalhes.

\section{Migração e idade}

O fato dos migrantes não constituírem uma amostra aleatória da população, mas sim indivíduos com características específicas, que respondem de maneira diferente a estímulos e obstáculos, é o que caracteriza a existência de uma "seletividade da migração". Dentre os diversos aspectos que atuam na seleção dos migrantes, um dos que mais se destaca é a idade.

Segundo Everett Lee, autor que há décadas vem sendo referência para os estudos das migrações, a força com que os estímulos e obstáculos à migração atuam sobre os indivíduos irá depender, em grande medida, do momento da vida em que eles se encontram, ou seja, sua etapa do ciclo de vida ${ }^{30}$. As migrações são tratadas por ele como "rites de passages". Segundo Lee, à medida que a idade avança, o indivíduo vai atravessando etapas do ciclo de vida que alteram suas preferências quanto à localização domiciliar e, consequentemente, estimulam ou inibem a migração.

Isso decorre do fato de existirem papéis socialmente estabelecidos para indivíduos de cada idade ${ }^{31}$. Segundo Settersten ${ }^{32}$, que estuda a relação entre envelhecimento e ciclo de vida, o lazer e o descanso são social e culturalmente direcionados para as idades iniciais e finais do ciclo de vida, enquanto nas idades intermediárias a prioridade (social) é o trabalho. Esses processos estruturam o ciclo de vida das pessoas e influenciam fortemente sua propensão para migrar. Dessa forma, cada sociedade ou organização social acaba determinando, através de suas características individuais, quais indivíduos configuram-se como provedores (produtores líquidos) e quais aqueles indivíduos são receptores (consumidores líquidos) de recursos ${ }^{33}$.

\footnotetext{
${ }^{29}$ LAWSON, Victoria A. Hierarchical households and gendered migration in Latin America: feminist extensions to migration research.

${ }^{30}$ LEE, Everett. Uma teoria sobre a migração.

${ }^{31}$ GLICK, Paul. The life cycle and social change.

32 SETTERSTEN, Richard. Aging and the life course.

${ }^{33} \mathrm{~A}$ interação entre características corporais do indivíduo e as condições da sociedade em que ele vive, isto é, a combinação de limitações impostas pelo corpo com a organização social graduam os níveis de dependia de cada um (MEDEIROS, Marcelo, DINIZ, Debora. Envelhecimento e deficiência).
} 
Esses níveis de dependência e capacidade de suporte, em sentido amplo (recursos financeiros, materiais, tempo, dedicação, habilidade), que têm forte influência na distribuição de poder de decisão familiar, são determinados, em grande parte, pelo estágio do ciclo de vida em que o indivíduo se encontra. Isso serve também para a capacidade de decisão sobre a migração e, consequentemente, a caracterização da mesma como um processo voluntário ou não.

Desse modo, quase sempre as crianças migram acompanhando os parentes, como pais e irmãos. Os jovens e os adultos, que são os grupos populacionais que mais migram, geralmente deslocam-se em busca de trabalho e realizam movimentos que possuem um maior grau de autonomia e voluntariedade. Ao envelhecerem, as limitações impostas pelo avanço da idade impõem, em alguns casos, a necessidade de migrar, seja acompanhando familiares seja em busca de residência próxima a locais que possuem instituições de suporte ao idoso ${ }^{34}$.

As regularidades observadas nos padrões etários de migração forneceram as bases para a elaboração de modelos etários de migração por Andrei Rogers e Luis Castro. A partir do cálculo de taxas específicas de migração por idade para diferentes populações, Rogers e Castro $^{35}$ constataram que, embora a intensidade (nível) com que os indivíduos de cada população migravam variasse consideravelmente, o perfil (padrão) exibido pelas taxas migratórias por idade, referentes a cada população, apresentava uma persistente regularidade.

Com base na ligação entre ciclo de vida e voluntariedade da migração, podemos pensar em um continuum de voluntariedade da migração, só que por idade. A FIGURA 2 apresenta, de forma esquemática, a junção do modelo etário de migração de Rogers e Castro com o continuum de voluntariedade da migração.

FIGURA 2 - Propensão migratória por idade e força de voluntariedade da migração

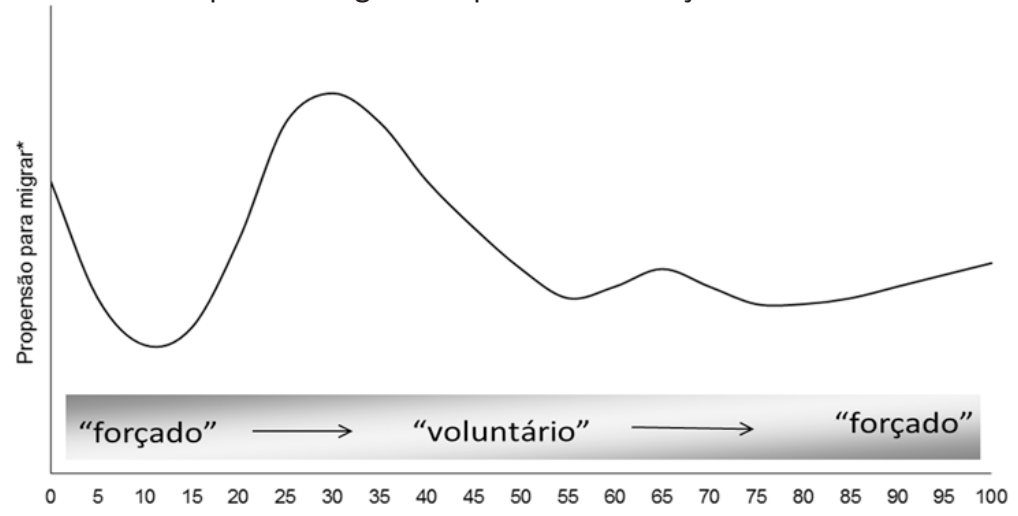

Fonte: adaptado de Rogers e Castro (op. cit.). * No modelo original é usada taxa de migração por idade.

${ }^{34}$ CAMPOS, Marden B., BARBIERI, Alisson Flávio. Considerações Teóricas sobre as migrações de idosos.

${ }^{35}$ ROGERS, Andrei, CASTRO, Luis. Model migration schedules. 
O modelo de migração de Rogers e Castro apresenta, esquematicamente, as variações da propensão migratória por idade. Em termos de voluntariedade da migração, podemos relacionar os "picos" migratórios localizados nas idades extremas, da infância e dos idosos, a deslocamentos com menor grau de voluntariedade, que se aproximariam de deslocamentos "forçados", no sentido de que estamos tratando neste trabalho, de que esses indivíduos possuem pouco ou nenhum poder de decisão quanto à migração. Por outro lado, os "picos" migratórios localizados nas idades adultas seriam caracterizados como "voluntários", no sentido de maior autonomia dos indivíduos quanto à capacidade de decisão da migração.

\section{Migração e sexo}

Os estímulos à migração de homens e mulheres são substancialmente diferentes, acarretando também em uma seletividade da migração em relação ao sexo. Essas diferenças são mostradas desde os primeiros estudos sistemáticos da migração, realizados por Ravenstein, no final do século XIX ${ }^{36}$. A seletividade da migração ao sexo baseia-se na diferença dos papéis estabelecidos para indivíduos de cada sexo na sociedade, qualificando as relações de gênero. Existe uma divisão de responsabilidades, direitos e obrigações entre homens e mulheres, prescritos pelo que Mason ${ }^{37}$ chama de "sistema de gênero". O sistema de gênero prescreve um conjunto de expectativas, socialmente construídas, sobre o comportamento de homens e mulheres. Desse modo, a migração, como um processo social que é, ocorre sob forte influência do sistema de gênero. As relações de gênero determinam a posição das pessoas na família, nos processos decisórios e, por isso, as oportunidades disponíveis e os constrangimentos que mulheres e homens devem considerar em suas migrações. Assim, as relações de gênero estão envolvidas em praticamente todos os aspectos do processo migratório, incluindo as conexões entre os locais de origem e destino, as estratégias de seleção e recrutamento dos migrantes, a razão de sexo exibida pelos fluxos migratórios e a participação no processo decisório de migração ${ }^{38}$.

Lawson $^{39}$ analisa os determinantes da seletividade da migração em relação ao sexo, com base em estudos de migração na América Latina. Segundo a autora, para compreender esses determinantes, é crucial analisar a dinâmica das relações de poder intradomiciliares. Para Lawson, as migrações de mulheres muitas vezes são determinadas pela divisão do trabalho (produtivo e reprodutivo) dentro dos domicílios e também pela segmentação do mercado de trabalho externo ao

\footnotetext{
${ }^{36}$ RAVENSTEIN, Ernest George. As leis das migrações.

${ }^{37}$ MASON, Karen O. Gender and demographic change: what do we know?

${ }^{38}$ RILEY, Nancy, GARDNER, Robert W. Migration decisions: the role of gender.

${ }^{39}$ LAWSON, op. cit.
} 
domicílio. O mesmo ponto de vista é defendido por Radcliffe ${ }^{40}$, que estuda as migrações de comunidades camponesas do Peru. Segundo afirma a autora, a perspectiva de gênero é a principal ferramenta conceitual para compreendermos a migração de camponeses. No sistema patriarcal em vigor nessas sociedades o trabalho feminino é sistematicamente desvalorizado e a mulher tem autonomia limitada, além de pouco poder de decisão. As relações de poder internas ao domicílio estão fortemente organizadas em torno de relações desiguais de gênero, que privilegiam os homens e criam uma dependência da mulher em relação a eles. Essa racionalidade está por trás da seletividade da migração em relação ao sexo. "Women leave at younger age than men, make more permanent moves to the cities, and terminate migration upon marriage" ${ }^{\prime 1}$. Nas áreas urbanas, as mulheres são recrutadas como empregadas domésticas, enquanto há maior demanda por homens nos trabalhos agrícolas das zonas rurais. Sendo assim, o homem e a mulher tendem a migrar para locais diferentes, de acordo com as estruturas de mercado de trabalho regionais ${ }^{42}$.

Segundo Guest ${ }^{43}$, a migração feminina é condicionada por relações de gênero, que variam, dentre outros aspectos, segundo a idade da mulher e sua posição no ciclo de vida. Por exemplo, nas sociedades tradicionais, as mulheres mais jovens permanecem na casa dos pais até casarem-se, ajudando nos afazeres domésticos. Ao casarem, vão viver com os maridos, cuidar dos filhos e dos pais idosos. Caso fiquem viúvas, podem mudar para perto dos filhos em busca de suporte.

Em resumo, tanto o sexo quanto a idade influenciam as relações de poder intrafamiliar que, ao interferirem no processo de tomada de decisão para a migração, qualificam os deslocamentos como processos voluntários ou involuntários.

\section{Discussão: características demográficas e a voluntariedade da migração}

Embora os deslocamentos populacionais sejam normalmente divididos entre migrações forçadas ou voluntárias, a maior parte das migrações dificilmente irá enquadrar-se em um desses tipos extremos. Combinações de vontade interior com forças externas ao indivíduo, em um constante embate entre agência e estrutura, alimentam o processo, o que culmina ou não na migração. Isso é ainda mais importante quando inserimos o componente familiar no processo migratório, tanto como unidade de tomada de decisão quanto como grupo migrante.

\footnotetext{
${ }^{40}$ RADCLIFFE, Sarah A. The Role of Gender in Peasant Migration: Conceptual Issues from the Peruvian Andes.

41 Ibidem, p. 137.

42 RADCLIFFE, Sarah A. Mountains, maidens and migration: gender and mobility in Peru.

${ }^{43}$ GUEST, Philip. The determinants of female migration from a multilevel perspective.
} 
Este artigo buscou discutir, conceitualmente, como a idade e o sexo atuam sobre o comportamento migratório, configurando tipos específicos de migração que podem ser considerados com um maior componente forçado ou voluntário. Para isso, mostrou a influência dessas variáveis na determinação de posições dos indivíduos nos processos de tomada de decisão para a migração, com base nas relações de poder que permeiam as relações familiares.

Cabe destacar que existe uma parte considerável das migrações que ocorrem com pouca ou nenhuma influência das famílias dos migrantes, embora, também nesses casos, a idade e o sexo continuem influenciando o comportamento migratório, dada a seletividade da migração a essas variáveis.

Ao discutir a noção do que é migração forçada ou voluntária, o artigo destacou como a demografia pode contribuir para essa discussão.

Cabe ressaltar, mais uma vez, que não foi nosso objetivo discutir as migrações com elevado grau de involuntariedade, que tradicionalmente têm sido chamadas de "migrações forçadas". Esses tipos de deslocamentos, em que o migrante é considerado "refugiado", já são alvo de extensa bibliografia e debate profícuo. O que se buscou foi, no intuito de perturbar as familiaridades, mostrar que outros tipos de movimentos espaciais também apresentam uma carga de involuntariedade que deve ser considerada nas análises de migração.

Para isso, inicialmente precisamos considerar que a maior parte dos indivíduos não migra só ou não tem a migração como um projeto exclusivamente pessoal. Estudos realizados no Brasil mostram que grande parte das migrações ocorre juntamente com a família ${ }^{44}$.

Ao mesmo tempo, é preciso atentar para o fato de que os indivíduos que se deslocam de maneira forçada (os considerados refugiados, por exemplo), muitas vezes trazem com eles outros indivíduos cujo estímulo migratório esteve fortemente determinado por relações de dependência, suporte ou afeto, que agiram como laços pessoais mais fortes do que o próprio motivo inicial da migração.

Por fim, resta uma última questão: como os aspectos discutidos se comportarão no futuro próximo e em que medida isso afetará as migrações? As mudanças observadas na sociedade estão alterando suas formações de classe, camadas sociais, ocupação, papéis dos sexos e da família. A maior participação das mulheres no mercado de trabalho, por exemplo, causa, segundo Beck ${ }^{45}$, uma revolução nas ordens ocupacionais, políticas e privadas convencionais. Desse modo, a mudanças nas formas de organização social implicarão em novos fenômenos e na necessidade de repensar o significado atual da mobilidade

\footnotetext{
${ }^{44}$ CAMPOS, Marden B. Estrutura Domiciliar de Migração: com quem os idosos migram?

${ }^{45}$ BECK, Ulrich, GIDDENS, Anthony, LASH, Scott. Modernização reflexiva: política, tradição e estética na ordem social moderna.
} 
espacial. Embora esse não tenha sido o objeto deste trabalho, os temas tratados podem contribuir essa discussão.

\section{Referências bibliográficas}

ALEXANDER, Jeffrey. Novo movimento teórico. Revista Brasileira de Ciências Sociais, n. 4, v. 2, 1987, p. 5-28.

BECK, Ulrich; GIDDENS, Anthony; LASH, Scott. Modernização reflexiva: política, tradição e estética na ordem social moderna. São Paulo: Editora da Universidade Estadual Paulista, 1997.

BERGER, Peter; LUCKMANN, Thomas. A Construção Social da Realidade: tratado de sociologia do conhecimento. Petrópolis: Vozes, 1966.

BORJAS, George. Labor Economics. New York: Mac Graw Hill, 1996.

CALDWELL, John. Towards a restatement of demographic theory. Population and Development Review, v. 2, 1976, p. 321-366.

CAMPOS, Marden B.; BARBIERI, Alisson Flávio. Considerações Teóricas sobre as migrações de idosos. Revista Brasileira de Estudos de População, v. 30, 2013, p. 69-84.

CAMPOS, Marden B. Estrutura Domiciliar de Migração: com quem os idosos migram? In XVIII Encontro Nacional de Estudos Populacionais, 2012, Aguas de Lindóia. Anais do XVIII Encontro Nacional de Estudos Populacionais. Campinas: ABEP, 2012. DAVIS, Kingslay. The theory of change and response in modern demographic history. Population index, v. 29, n. 4, 1963, p. 345-366.

DE HAAS, Hein. Migration and development: a theoretical perspective. Working Paper n. 9. Oxford: International Migration Institute, 2008.

FAIST, Thomas. The Crucial Meso Level. In MARTINIELLO, Marco; RATH, Jan. (eds.). Selected Studies in International Migration and Immigrant Incorporation. Amsterdam: AUP, 2010, p. 59-90.

FOUCAULT, Michel. Microfísica do poder. Rio de Janeiro: Ed. Graal, 1979.

FOUCAULT, Michel. O sujeito e o poder. In DREYFUSS, Hubert; RABINOW, Paul. Uma trajetória filosófica: para além do estruturalismo e da hermenêutica. Rio de Janeiro: Forense, 1995, p. 231-249.

FOUCAULT, Michel. Vigiar e punir: nascimento da prisão. Petrópolis: Vozes, 2008.

GAUDEMAR, Jean-Paul. Mobilidade do trabalho e acumulação do capital. São Paulo: Editorial Estampa, 1977.

GIDDENS, Anthony. The Constitution of Society: outline of the theory of structuration. Berkeley and Los Angeles: University of California Press, 1984.

GLICK, Paul. The life cycle and social change. Family Relations, v. 38, n. 2, 1989, p. 123-129.

GRANOVETTER, Mark. The Strength of Weak Ties. American Journal of Sociology, v. 78, n. 6, 1973, p. 1360-1380.

GUEST, Philip. The determinants of female migration from a multilevel perspective. 
In Internal migration of women in developing countries. New York: UNITED NATIONS, 1993.

HUGO, Graeme. Environmental concerns and international migration. International Migration Review, v. 30, n. 1, 1996, p. 105-131.

KAHNEMAN, Daniel. Rápido e devagar: duas formas de pensar. Editora Objetiva, 2012.

LAWSON, Victoria A. Hierarchical households and gendered migration in Latin America: feminist extensions to migration research. Progress in Human Geography, London, v. 22, n. 1, 1998, p. 39-53.

LEE, Everett. Uma teoria sobre a migração. In MOURA, Hélio A. (org.). Migração interna, textos selecionados: teorias e métodos de análise. Fortaleza: BNB, 1980, p. 89-114.

LITWIN, Howard. The Social Network of Elderly Immigrants: an analytic typology. Journal of Aging Studies, New York, v. 9, n. 2, Summer 1995, p. 155-174.

MASON, Karen O. Gender and demographic change: what do we know? Liege, Belgique: International Union for the Scientific Study of Population, 1995.

MASSEY, Douglas. Social structure, household strategies and the cumulative causation of migration. Population Index, Princeton, v. 56, n. 1, 1990, p. 3-26.

MEDEIROS, Marcelo; DINIZ, Debora. Envelhecimento e deficiência. In CAMARANO, Ana Amélia (org.). Os novos idosos brasileiros: muito além dos 60? Rio de Janeiro: IPEA, 2004.

MINCER, Jacob. Family Migration Decisions. The Journal of Political Economy, Chicago, v. 86, n. 5, p. 749-773, 1978.

PETERSEN, William. A General Typology of Migration. American Sociological Review, v. 23, n. 3. 1958, p. 256-266.

RADCLIFFE, Sarah A. Mountains, maidens and migration: gender and mobility in Peru. In CHANT, Sylvia. Gender and migration in developing countries. London: Belhaven Press, 1992.

RADCLIFFE, Sarah A. The Role of Gender in Peasant Migration: Conceptual Issues from the Peruvian Andes. Review of Radical Political Economics, v. 23, n. 3-4, 1991, p. 129-147.

RAVENSTEIN, Ernest George. As leis das migrações. In MOURA, Hélio A. (org.). Migração interna, textos selecionados: teorias e métodos de análise. Fortaleza: BNB, 1980.

REZENDE, Dimitri Fazito. Reflexões sobre os sistemas de migração internacional: proposta para uma análise estrutural dos mecanismos intermediários. Tese de Doutorado. Belo Horizonte: CEDEPLAR/UFMG, 2005.

RILEY, Nancy; GARDNER, Robert W. Migration decisions: the role of gender. In UNITED NATIONS. Internal migration of women in developing countries. New York, 1993.

ROGERS, Andrei; CASTRO, Luis. Model migration schedules. Luxemburg: International Institute for Applied Systems Analysis, 1981. 
SETTERSTEN, Richard. Aging and the life course. In BINSTOCK, Robert; GEORGE, Linda (eds.). Handbook of aging and the social sciences. Burlington: ELSEVIER Academic Press, 2006.

SINGER, Paul. Migrações internas: considerações teóricas sobre o seu estudo. In MOURA, Hélio A. (org.). Migração interna, textos selecionados: teorias e métodos de análise. Fortaleza: BNB, 1980.

SJAASTAD, Larry. Os custos e os retornos da migração. In MOURA, Hélio (org.). Migração interna, textos selecionados: teorias e métodos de análise. Fortaleza: BNB, 1980.

STARK, Oded; BLOOM, David. The new economics of labor migration. AEA Papers and Proceedings: frontiers in demographic economics, v. 75, n. 2, 1985, p. 173178.

STARK, Oded; TAYLOR, J. Edward. Migration incentives, migration types: the role of relative deprivation. The Economic Journal, v. 101, n. 408, 1991, p. 1163-1178.

TAYLOR, J. Edward. Differential migration, networks, information and risks. In STARK, Oded. Migration, human capital and development. Greenwich: Connecticut, Jai Press, 1986, p. 147-171.

THALER, Richard H.; MULLAINATHAN, Sendhil. How behavioral economics differs from traditional economics. In HENDERSON David R. (ed.). The Concise Encyclopedia of Economics. Indianapolis: Liberty Fund, 2007.

TURNER, Jonathan. The theory of structuration. American Journal of Sociology, v. 91, n. 4, 1986, p. 969-977.

VIINAMÄKI, Heimo; KUMPUSALO, Esko; MYLLYKANGAS, Markku; SALOMAA, Sisko; KUMPUSALO, L., KOLMAKOV, S., ILCHENKO, I., ZHUKOWSKY, G.; NISSINEN, A. The Chernobyl accident and mental wellbeing - a population study. Acta Psychiatrica Scandinavica, v. 91, n. 6, 1995, p. 396-401.

\section{Abstract}

\section{Demographic attributes and migration decision process}

Although the population movements are usually divided between forced or voluntary, most migration will hardly fit into one of these extreme types. The aim of this paper is discuss conceptually as age and sex of the migrants act upon migratory behavior by setting specific types of displacements that have different levels of willingness. We will stress the power relations involved in the decision making process for migration, which determines that the migrations of many individuals are involuntary phenomenon, to the extent that they do not participate or do not have their interests taken into account in the decision making process. The article stress the significance of considering that the majority of individuals do not migrate alone as well as do not have migration as a uniquely personal project and, even that individuals involved in forced migration, so often cause the migration of other individuals whose migration stimulus is determined by relations of dependence, support or affection. Thus, highlights the importance of being 
alert to changes in the forms of social organization and their implications for the current meaning of the spatial mobility.

Keywords: forced migration, selectivity, power relations.

Recebido para publicação em 08/08/2014 Aceito para publicação em 02/07/2015 Received for publication in August, $08^{\text {th }}, 2014$ Accepted for publication in July, $02^{\text {nd }}, 2015$

ISSN impresso: 1980-8585 ISSN eletrônico: 2237-9843 http://dx.doi.org/10.1590/1980-85852503880004514 